\title{
Review of remote sensing methodologies for pavement management and assessment
}

\author{
E. Schnebele • B. F. Tanyu • G. Cervone · N. Waters
}

Received: 10 October 2013 / Accepted: 9 February 2015 / Published online: 7 March 2015

(C) The Author(s) 2015. This article is published with open access at SpringerLink.com

\begin{abstract}
Introduction Evaluating the condition of transportation infrastructure is an expensive, labor intensive, and time consuming process. Many traditional road evaluation methods utilize measurements taken in situ along with visual examinations and interpretations. The measurement of damage and deterioration is often qualitative and limited to point observations. Remote sensing techniques offer nondestructive methods for road condition assessment with large spatial coverage. These tools provide an opportunity for frequent, comprehensive, and quantitative surveys of transportation infrastructure.

Methods The goal of this paper is to provide a bridge between traditional procedures for road evaluation and remote sensing methodologies by creating a comprehensive reference for geotechnical engineers and remote sensing experts alike.

Results A comprehensive literature review and survey of current techniques and research methods is provided to facilitate this bridge. A special emphasis is given to the
\end{abstract}

E. Schnebele $(\bowtie) \cdot$ G. Cervone $\cdot N$. Waters

GeoInformatics and Earth Observation Laboratory (GEO), Department of Geography and Institute for CyberScience, The Pennsylvania State University, 302 Walker Building, University Park, PA 16802, USA

e-mail: eschnebe@gmu.edu

B. F. Tanyu

Department of Civil, Environmental, and Infrastructure Engineering, George Mason University, 4400 University Drive, Fairfax, VA 22030, USA

N. Waters

Emeritus of Geography at The University of Calgary,

2500 University Drive, Calgary, AB T2N 1N4, Canada challenges associated with transportation assessment in the aftermath of major disasters.

Conclusion The use of remote sensing techniques offers new potential for pavement managers to assess large areas, often in little time. Although remote sensing techniques can never entirely replace traditional geotechnical methods, they do provide an opportunity to reduce the number or size of areas requiring site visits or manual methods.

Keywords Road assessment - Remote sensing - Civil engineering

\section{Introduction}

The importance of incorporating remote sensing into geotechnical and geological engineering practices has long been recognized by the United States (US) National Research Council [95]. Recently, many US departments of transportation are integrating more remote sensing techniques into their standard methodologies for pavement management and assessment. Futhermore, the integration of geospatial tools and techniques in transportation management is a growing research agenda [99]. However, many geo-transportation engineers do not have an educational or practical background in remote sensing and many in the remote sensing community are unaware of the specific needs of geo-transportation engineers. Therefore, this paper is provided as a bridge between these two disciplines by serving as a reference tool as well as a way to initiate interdisciplinary research and practice collaborations. We discuss commonly used, traditional geotechnical methods and present an overview of recent remote sensing applications which may augment or be used as alternatives. 
We define "remote sensing" as any surveying method which does not require physical contact with the road surface or subsurface. This paper does not intend to imply that remote sensing may be used to replace all traditional in situ methods. However, if used appropriately, remote sensing may provide tools for rapidly surveying broad areas. Once problem areas are identified, specific conditions may then require the use of traditional road assessment methods.

Because remote sensing is capable of rapidly collecting information over wide areas, it has become a valuable method for assessing damage to infrastructure and buildings following major disasters. Using remote sensing for the analysis of road structure or accessibility following disasters is a new research agenda.

\subsection{History of roads and the need for assessment}

Unlike the stone roads constructed in ancient times, roads today are not designed or constructed to last forever, mainly for economical reasons. In most US states, roads are typically designed to last 15 to 20 years. Though, with frequent and proper maintenance, the design life may be extended considerably [84]. Typically, the cost of reconstruction of a deteriorated road due to lack of maintenance may be more than three times the cost of preserving a frequently maintained road [1]. Road conditions are an important factor in the US economy and leading civil engineering institutions, such as the American Society of Civil Engineers (ASCE), continue to produce articles regarding the need to improve roads and other infrastructures. According to [1], currently half of the major roads in the US are considered in poor condition with almost $25 \%$ of roads in urban areas (and in some areas even up to $60 \%$ ) considered poor. Researchers such as [119] have been reviewing the conditions of America's highways since 1983 to provide awareness to the general public and legislators.

The cost of maintenance and rehabilitation is high. In 2008 , an estimated $\$ 182$ billion were spent in the US on capital improvements and maintenance of federal highways. ${ }^{1}$ Although billions are spent annually, many consider this insufficient. For example, the ASCE currently gives the nation's transportation infrastructure (which includes not only roads and bridges, but dams, rail, levees, etc.) an overall grade of $\mathrm{D}$ (on a traditional grading scale ranging from A-F) and estimates $\$ 2.2$ trillion in improvements are needed. ${ }^{2}$

The development of road and bridge inspection and maintenance standards were developed in the US following the collapse of the Silver Bridge in 1967. In 1971, the National Bridge Inspection Standards (NBIS)

\footnotetext{
${ }^{1}$ http://www.fhwa.dot.gov

${ }^{2}$ http://www.infrastructurereportcard
}

were implemented as a result of the Federal-Aid Highway Act of $1968 .^{3}$ The development of a rating method for pavement resulted in the US Army Corps of Engineers Pavement Condition Index (PCI) which "measures pavement structural integrity and surface operational conditions" which are "calculated based on measured pavement distress types and severity levels" [113]. More recently, in 1987 the US Department of Transportation's Strategic Highway Research Program sponsored the Long-Term Pavement Performance Program (LTPP) to identify, collect, and catalog pavement defects and signs of deterioration [87].

A pavement's condition is assessed from data which measure information such as the rideability, surface distress, structure, and skid resistance of the road [57]. Many of the methods utilized for the NBIS, PCI, and LTPP require point data gathered in situ. For example, a measurement of pavement condition using the PCI requires a manual survey and application of the American Society for Testing and Materials (ASTM) standards (ASTM standards are used to promote health and safety as well as the reliability of products, materials, and systems ${ }^{4}$ ), while the Distress Identification Manual for the LTPP provides descriptions of all types of distresses such as cracks, potholes, rutting, and spalling in flexible and rigid pavements as well as methods for measuring these distresses [87].

Because road networks in Europe and the US are so extensive, it is not feasible to use traditional approaches to survey all existing roadways for their rideability and integrity of road structure. Remote sensing methods offer tools to replace or complement existing traditional methods and can serve many needs of transportation civil engineers. In addition to the difficulties associated with creating a comprehensive evaluation of the over $6,000,000 \mathrm{~km}$ of roads in the US from point data, other factors also restrict frequent, cost effective, and comprehensive road evaluations. Some of these limiting factors include time (roads need to be closed off during inspections causing transportation disruption), site work on highways can be hazardous for inspectors, manual collection methods which often require trained and experienced inspectors, and the use of destructive techniques. Also, many inspections are descriptive in nature making comparative measuring difficult.

Remote sensing techniques provide alternative methods for transportation assessment along with high spatial and temporal resolutions. These techniques can be implemented from various platforms, including moving vehicles, unmanned aerial vehicles (UAVs), airplanes, and satellites. Along with multiple platform options, sensors use different parts of the electromagnetic spectrum and contribute to the identification and the measurement of the surface and

\footnotetext{
${ }^{3}$ http://www.fhwa.dot.gov

${ }^{4}$ http://www.astm.org
} 
subsurface defects. These techniques offer non-destructive evaluation methods as compared to traditional procedures such as coring and field surveys. The use of remote sensing in transportation research is becoming an important and economically advantageous area of exploration.

In addition, the utilization of remote sensing methods is not limited to the identification and analysis of pavement defects and distress from weathering or service loads. There are many applications, such as tasking data collection from air- and space-borne platforms, which allow for regional scale identification of destruction during and after natural or anthropogenic disasters. Currently, the utilization of multi-source and multi-spectral data can provide enhanced identification of infrastructure destruction, as well as timely information regarding the trafficabililty of road networks after a disaster.

\section{Road types and profiles}

For most people, roads are just a layer of asphalt or concrete that is constructed over dirt (soil) to create a smooth surface to allow vehicular traffic. In reality, roads consist of several layers of material selected, designed, and constructed following specific US Federal and State design and material guidelines or specifications. Roads are generally categorized as unpaved or paved with paved roads typically classified as flexible, rigid, or composite systems. The subsurface layer varies with road type and plays a major role in the performance of the road [60]. In order to assess road conditions, it is important to understand typical road profiles.

\subsection{Unpaved roads}

Unpaved roads are typically constructed using a mixture of gravel placed and compacted over finer-grained soil such as clay or silt (or mixtures of these soils) (Fig. 1a). The finer-grained soil may be naturally deposited as part of the geological cycle or constructed as a fill as part of an artificially constructed structure such as an embankment or on top of an earth retaining structure. These finer-grained soils form the foundation of the roadway and are referred to as the subgrade [72]. The thickness, gradation, and type of gravel placed over the subgrade will vary based on the availability of the material close to the construction site as well as the subgrade type. If the subgrade consists of very soft soils, then a gravel with a maximum grain size is used to minimize the total deflection (rutting). If the size of the aggregate becomes too coarse, additional finer grained aggregate is mixed in with the coarser aggregate to fill voids and create a smoother surface. The thickness of the gravel layer is usually selected based on the local experience, although there are generally accepted unpaved road design methodologies [43]. It should be noted it is not uncommon to have gravel layers above subgrade in excess of $1 \mathrm{~m}$ if the subgrade or the gravel are not of high quality.

\subsection{Paved roads}

Paved roads are typically categorized as either a flexible or rigid pavement system. Sometimes, as part of the reclamation, the old road is not completely removed prior to construction of the new road and is referred to as a composite pavement [60]. The major difference between flexible and rigid pavement systems is the application of a bituminous surface layer (e.g., asphalt layer) in a flexible pavement or a Portland cement concrete layer in a rigid pavement system. In general, regardless of the type, pavement systems are constructed with the highest quality materials on the top where traffic stresses are greatest [60]. The thickness of the layers within the pavement system will typically decrease as constructed over subgrade due to the increased cost of the materials.

Following the subgrade layer is the application of a subbase layer. This layer is constructed to provide foundational support for the subsequent, higher layers if the subgrade is insufficient. The subbase is constructed by one of the following methods: (1) physically improving the subgrade with compaction and placing a coarse aggregate over the existing soil; (2) removing a portion of the soft subgrade and replacing it with more suitable soil; (3) adding chemical additives into the ground followed by compaction. The materials used for the subbase layer are similar to the materials used for unpaved roads but it is important to note, for approximately the last 20 years, transportation engineers also commonly use materials other than natural soils. Sometimes the soil will be reinforced with fabric-like materials such as woven or nonwoven geotextiles or materials resembling plastic (e.g., geogrids or geocells) [32, 67, 132]. Additionally, the natural soil can be completely replaced with recycled materials (e.g., industrial by-products such as foundry sand, foundry slag, bottom ash, or fly ash) [122]. The thickness of the subbase layer is usually constructed in the order of $450-600 \mathrm{~mm}$ but will vary based on the properties of the subgrade.

The base layer serves as the drainage layer for the pavement system. It is commonly constructed over the subbase but may be placed directly over the subgrade if the subgrade soils are classified as competent for road construction [60]. It is built using a high quality aggregate containing very few or no-fines [72]. It is also possible to use recycled materials in the base layer such as a recycled concrete aggregate $[14,137]$. The typical thickness of the base layer may range between 100-300 $\mathrm{mm}$ for flexible pavement systems and up to $500 \mathrm{~mm}$ for rigid pavement systems. 
For flexible pavements, the layers above the base layer consist of (from the bottom up) a binder course and a surface course (Fig. 1b). The binder course consists of a mixture of larger aggregates and asphalt and is typically constructed to be between $50-100 \mathrm{~mm}$ thick. The surface course is the top of the pavement and is usually constructed from dense asphalt. As the crown of the pavement system, this layer must be constructed to resist distortion under traffic, be reasonably waterproof, smooth, and provide skid resistance. On rigid pavements, the layer above the base layer typically consists of 150-300 mm thick Portland cement concrete (Fig. 1c). The surface of the rigid pavement is much stiffer than the surface of the asphalt pavement and is customarily constructed directly over the base course (sometimes without having a subbase layer underneath). Although the concrete for rigid pavements is constructed in several different ways, these types of pavement systems will contain some form of reinforcement elements such as dowels, wire mesh, or deformed bars within the concrete.

Composite pavement is typically a combination of both flexible and rigid pavement. Usually, concrete is used at the bottom of the two layers, providing a strong foundation to support heavy traffic with the asphalt on top providing a smooth riding surface. As with other pavement systems, these types of systems may also include a base layer depending on the subgrade conditions. Due to the high cost of constructing these systems, composite pavements are limited to less than $1 \%$ of the paved roads in the US [60].

\section{Common road defects}

Roads are considered problematic typically when they start to indicate issues related to their (1) structural adequacy, (2) skid resistance, or (3) surface defects. Some of these properties are more suited for remote sensing evaluations than others.

\subsection{Structural adequacy}

Structural adequacy is associated with the load transfer efficiency of the road and is evaluated using measured
Fig. 1 Profiles of unpaved, flexible, and rigid pavements

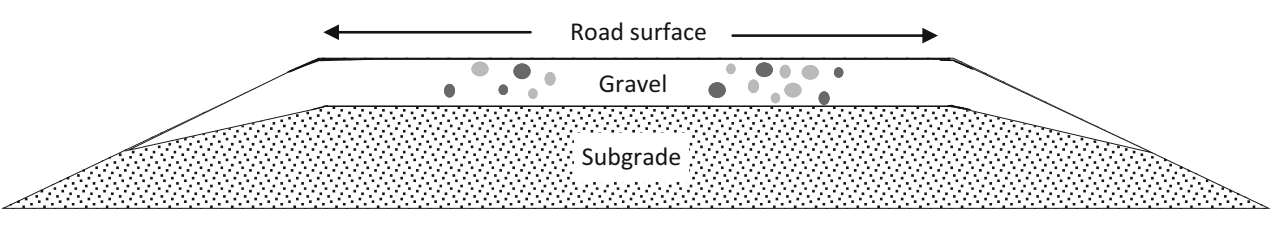

A.) Unpaved road profile

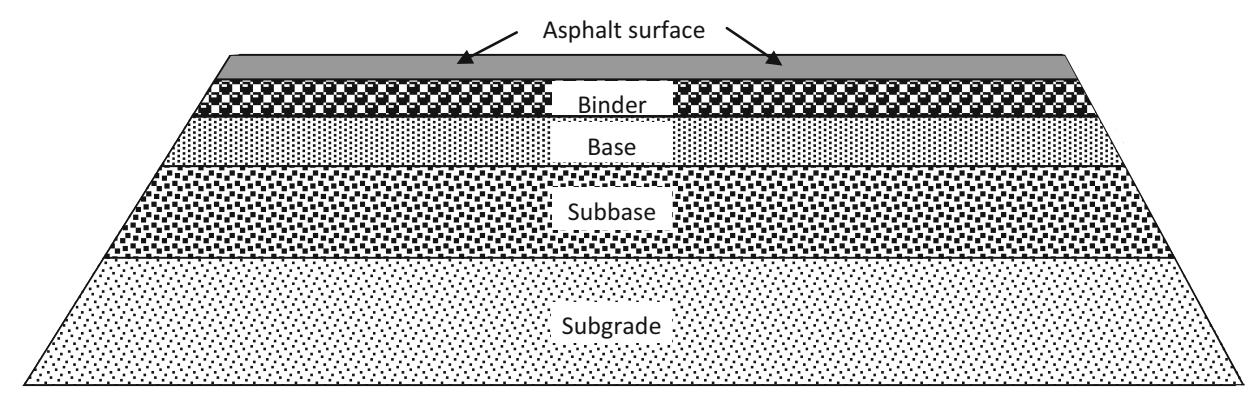

B.) Flexible pavement profile

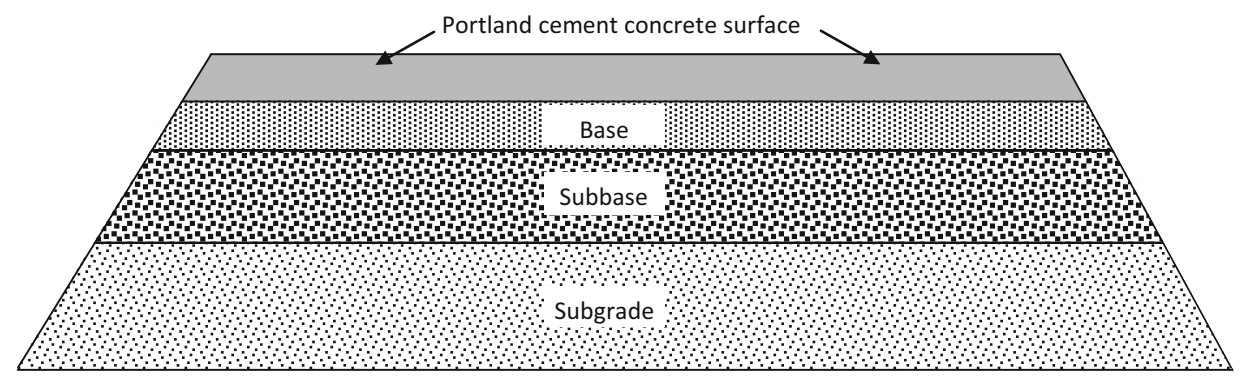

C.) Rigid pavement profile 
deflections inflicted at the surface of the pavement. The deflections are created by applied loads such as static or slowly moving loads (e.g., Benkelman beam, California travelling deflectometer, and LaCroix deflectometer), steady-state vibration (e.g., Dynaflect and road rater), or impulse loads (e.g., falling weight deflectometers). The measured deflections are used to backcalculate elastic moduli or the load-transfer efficiency of the subsurface layers. Predicting this type of behavior via remote sensing, without being able to apply pressure to the surface, is difficult.

\subsection{Skid resistance}

Skid resistance is a property of the pavement which creates enough surface friction for vehicles to maintain control, especially during wet conditions. Although skid resistance is also a function of the driver and vehicle characteristics, surface conditions such as bleeding or polished asphalt or smooth macro-texture are used as indicators to identify the potential for skid resistance hazards. Skid resistance of a road is typically measured with a locked wheel trailer procedure where the trailer is pulled at a certain constant speed while the braking system of the test tire is actuated to lock the tire on a wet road surface.

Recently, remote sensing has been applied to measure the macro and micro-texture of the surface. [138] used multiple laser scanners to identify surface macro-texture at a $1 \mathrm{~mm}$ resolution collected at highway speeds. [21] used spectral and fractal analysis to identify micro-texture changes due to a differential loss of mineral constituents from tire polishing. [83] illustrate how 3D photogrammetry can capture micro-texture changes from polishing.

\subsection{Surface defects}

Surface defects are visible indicators of road serviceability and are closely related to roughness, which is often utilized for road condition evaluations. There are a variety of available remote sensing applications for the identification, measurement, and classification of surface defects and thus, also to provide estimations of road roughness. The following subsections describe the usual features associated with surface defects that may be identified with remote sensing methods.

\subsubsection{Unpaved roads}

Below is a summary of the most common visible defects/deformations which typically affect unpaved road performance $[8,41,44,60,96,104,125,133] . .^{5}$

\footnotetext{
${ }^{5}$ http://www.wrapair.org
}

- Potholes: Bowl-shaped holes caused by the movement of loose surface material under traffic loads. They become problematic if their depth and diameter becomes greater than $25 \mathrm{~mm}$ and $200 \mathrm{~mm}$, respectively.

- Rutting: Longitudinal deflections along the wheel-path caused by permanent deformation or compaction of road material under traffic loading. Unpaved roads constructed over a subgrade with a high clay content or with minimal surface coarse aggregate are prone to rutting in wet conditions.

- Corrugations: Evenly spaced transverse ridges caused by traffic actions in conjunction with lose of aggregate. They often occur in areas with heavy acceleration and deceleration traffic actions.

- Erosion and gravel loss: This occurs from a sweeping action of traffic or free flowing water across road surface. It may severely alter the cross-section of the road causing safety concerns and poor rideability.

- Pulverization: A break down of surface aggregate particles under traffic load creating excessive dust with rolling wheels. Although pulverization may not hinder the riding quality of the road surface, it may create safety hazards and discomfort both to the drivers and in areas within the vicinity.

\subsubsection{Flexible pavement}

Below is a summary of the most common visible defects/deformations which typically affect flexible pavement performance [27, 41, 60, 96, 104, 112, 125].

- Cracking: There are three types of cracking common to flexible pavement: surface, fatigue, and movement (term used for the purpose of this paper) cracking.

Surface cracking is associated with aging and deterioration of the surface bituminous layer due to shrinking and hardening. It is not associated with applied load and may appear along the full-width of the pavement. Thermal cracking, a subset of surface cracking, is common in northern regions of the US where temperatures can fall below $-23{ }^{\circ} \mathrm{C}$. Thermal cracking forms when the thermal stress on the pavement is greater than the fracture strength. Thermal cracking may also occur in milder climates if the asphalt becomes hardened due to aging or if the road was constructed with hard asphalt.

Fatigue cracking is associated with traffic loading and appears along the vehicle wheel path. It is often associated with deformation along the asphalt. It is also referred to as alligator cracking because it resembles the skin of the alligator or a chicken-wire pattern. Early signs can be detected from observations of fine parallel longitudinal cracks along the wheel-paths. 
Movement cracking is associated with the movement of the subsurface layers such as the subgrade, concrete slab below the asphalt, culvert, or bridge joints. It typically appears transverse or longitudinal and follows the dimensions of the problematic area underneath the surface.

- Potholes: Bowl-shaped holes similar to those in unpaved roads, typically form as a result of untreated cracks. They are problematic if depth and diameter becomes greater than $25 \mathrm{~mm}$ and $150 \mathrm{~mm}$, respectively.

- Rutting: These surface deformations occur along the wheel-path as similarly observed in unpaved roads. They are caused mainly by the deformation of the subsurface layers as a result of the surface traffic load propagating to subsurface layers.

- Swelling: An upward bulge on the pavement surface usually caused by frost action or by swelling subgrade soils. Swelling can appear as a localized bulge or a long gradual wave.

- Shoving: These defects are similar to rutting, however, they typically occur in areas where vehicles frequently stop and start. They are result of shear forces induced by traffic loading and form as localized longitudinal or transverse displacements.

- Raveling: This is the result of traffic abrasive action and is indicated by a progressively damaged surface downward into the pavement layers, such as the binder course, and aggregate loss within the binder course.

- Bleeding of asphalt: Shiny black surface caused by liquid asphalt typically migrating in hot temperatures along the pavement surface. It has a large impact on skid resistance of the asphalt.

- Polished asphalt: Wearing off of the sharp edges in the surface aggregate from traffic. It results in a smooth slippery surface and has a large impact on skid resistance of the asphalt.

As a result of some or all of these defects, the flexible pavement may lose its smoothness (become too rough), skid resistance, macro-texture (ability to drain under wet conditions), and overall rideability quality.

\subsubsection{Rigid pavement}

Below is a summary of the most common visible defects/deformations which typically affect rigid pavement performance [22, 26, 34, 36, 41, 60, 93, 134].

- Cracking: In general, there are four types of cracking in rigid pavement: surface, durability, cluster, and diagonal cracking.

Surface cracking is associated with aging and deterioration of the surface concrete layer and does not protrude deeply into the concrete slab. It may form as a series of random cracks, longitudinally parallel to the pavement centerline, or pop-outs of small pieces of pavement broken loose from the surface.

Durability cracking forms adjacent to joints, cracks, or free edges of the pavement and is initiated at the intersection of cracks and a free edge. It usually appears as closely spaced, crescent-shaped, dark colored, hairline cracking. It is mainly attributed to the response of the material properties to freeze-thaw cycles and aggregate pore structure.

Cluster cracking is a closely spaced transverse cracking occurring in groups of three or more with spacing ranging between $150-600 \mathrm{~mm}$. This is more of a characteristic of continuously reinforced concrete pavements and is typically associated with changes in conditions below the surface, such as settlement within subsurface layers, poor drainage conditions, and high base friction. However, it may also form as a result of inadequate concrete thickness, lack of concrete consolidation, and construction of concrete during high temperatures. It usually occurs early in the life of the pavement.

Diagonal cracking indicates an existing foundation problem (settlement or expansion) and forms in a direction oblique to the pavement centerline.

- Blow-ups: A localized upward movement of the concrete pavement surface at cracks or joints typically occurring in high temperatures and precipitation. They occur in older systems where the expansion space within the concrete pavement is insufficient for expansion. Depending on the magnitude of the blow-up, the road may have to be closed to traffic.

- Faulting: Created by a movement along the joint or a crack creating an elevation difference. The name is taken from the movement observed in nature after earthquakes, however, the cause of this type is not typically associated with earthquakes (although they may also form after earthquakes). Faulting occurs when the concrete slab losses its support due to erosion or settlement of the subsurface layers. It is one of the most prominent defects and has a direct impact on road rideability.

- Spalling: Breaking, cracking, or disintegration of the slab edges within $0.6 \mathrm{~m}$ of a joint or crack. Spalling is generally associated with a surface weakness within the concrete but if allowed to progress and deepen, will be an indicator of a structural weakness within the concrete.

- Punch-outs: An area enclosed by two closely spaced transverse cracks, a short longitudinal crack, and the pavement edge (resembling a box cut out on the edge of the pavement). It typically initiates from traffic loading 
of the transverse cracks and is also aided by corrosion of the steel within the concrete.

- Pumping: This results from water seeping into the pavement system or ejecting out of the system through the cracks or joints. In some cases it is detectable by deposits of fine material left on the pavement surface. It is caused by inadequate concrete slab thickness and erodible underlying layers.

- Joint seal damage: This results from joint deterioration, enabling a significant amount of water to infiltrate into the joint from the surface, weed growth at the joint, or intrusion of particles into the joint. It may lead to development of closely spaced transverse cracks or large numbers of interconnected cracks near the joint.

As for the flexible pavements, based on these defects the road may show low rideability quality or eventually be closed to traffic.

\section{Traditional assessment of road surface defects}

Many road authorities still utilize methods requiring inperson "walk and look" measurements while others use mechanical devices to measure certain surface defects. Manual walking surveys may include $100 \%$ of the area to be surveyed, measured, recorded, and sometimes mapped. [87] provide a comprehensive manual regarding walking surveys of road surface defects using visual inspections and in situ field measurements. The US National Cooperative Highway Research Program (NCHRP) Synthesis 334 summarizes the methods of capturing surface distresses utilizing both in-person surveying as well as semi-automated and automated methods including riding surveys [81]. Traditional riding surveys estimate the severity of road defects while driving along the shoulder at slower speeds or, less accurately, while driving on the pavement at normal speeds.

The transition from manual to automated data collection has increased over the past 20 years. According to the NCHRP Synthesis 203, in 199440 states in U.S. were surveying surface defects predominantly using manual methods [47]. In 2004, of the 45 state agencies surveyed, only 17 were still utilizing manual survey methods [81]. The remaining 28 state agencies were implementing some form of digital or analog video surveillance along with automated systems. As of 2007, several well-established firms were providing commercially available semi-automated methods [117]. [124] recently presented a software package based on photogrammetric methods to fully assess the severity of potholes using automated systems. Today, most departments of transportation (DOTs) are open to vendor demonstrations to implement fully automated systems. Some DOTs, such as the Virginia Department of Transportation, have developed data collection requirements to guide vendors on how to generate automated data of acceptable quality [136]. It is clear that many state and local agencies are implementing more automated and remote sensing methods but currently there is no single, well-accepted automated system embraced by all DOTs to evaluate surface defects.

Traditional methods provide accurate and valuable information but obtaining these data can be time consuming. Furthermore, when the interpretation of the severity of the damage is determined based on judgment (even though there are well established rating criteria), the results can vary. Therefore, the integration of more automated and semiautomated remote sensing methods is inevitable and may provide valuable results when generated/interpreted by a computer. The outcome of these surveys is likely to be less expensive, more consistent, faster, and cover wider areas.

The remainder of this article offers an overview of available remote sensing tools to provide industry and government agencies guidance in the selection of appropriate methods for accomplishing specific road assessments.

\section{Overview of remote sensing methods}

The Sun is the primary source of energy for the Earth. This energy, or electromagnetic (EM) radiation, travels through space in the form of waves which are absorbed, reflected, or scattered by the Earth's atmosphere and its surface. The amount of energy emitted or absorbed by an object is a function of temperature, and every object with a temperature above 0 degrees Kelvin emits EM radiation. Plank's equation defines a theoretical relationship between temperature and EM energy emitted, which is used to define blackbodies. Stars most closely approximate the theoretical blackbody emission, whereas all other objects, called greybodies, have emissions lower than this theoretical maximum.

Peak emission is a function of temperature, with wavelength decreasing as temperature increases. Therefore, the sun which has an approximate temperature of 6000 degrees Kelvin peaks in the visible region of the EM spectrum, whereas the Earth, with an average temperature of about 300 degrees Kelvin peaks in the thermal infrared region. This relationship is governed by the Wien law [50].

\subsection{Remote sensing techniques}

The range of electromagnetic radiation is summarized by wavelength or frequency by the electromagnetic spectrum (Fig. 2). Utilizing different regions of the electromagnetic spectrum allows scientists to gather information in a variety of ways, from photographs to thermal images. For example, data collected from the visible spectrum, such as 
Fig. 2 Electromagnetic Spectrum as a function of frequency. Length of the wave signal is compared to physical objects. Source: NASA

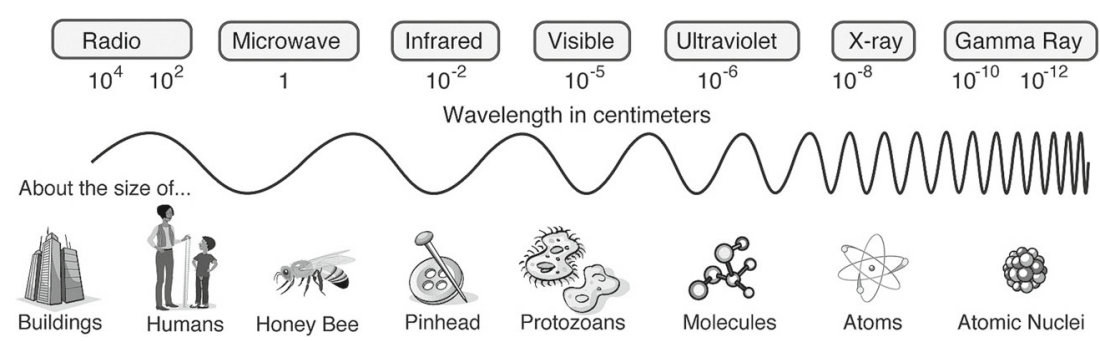

photographs, are the most common method of remote sensing for pavement analysis. The use of ground penetrating RADAR (GPR) has long been employed by geotechnical engineers to detect subsurface anomalies. While variations in temperature identified in the infrared region can be used to locate defects and cracks in pavement. Techniques such as laser scanning and hyperspectral imagery also contribute to identifying and locating defects and distress, often more rapidly than manual surveying. Sensors, mounted on various types of platforms, gather electromagnetic radiation emitted or reflected from the object or area of interest. The spatial, temporal, and spectral resolutions of the remote sensing data collected vary depending on the type of sensor and platform utilized.

\subsection{Remote sensing platforms}

Data can be collected remotely from any number of places or platforms. The following section summarizes the most common platforms used to gather remote sensing data.

\subsubsection{Satellite}

Imagery collected from satellites provides the largest spatial coverage of any remotely sensed data and is used in multiple disciplines ranging from the earth sciences to military reconnaissance. Although these data can cover extremely vast regional or continental areas in a single image; data collection, quality, and usability can be limited by revisit times, atmospheric interferences, and spatial resolution.

A satellite's orbit and inclination will determine data coverage and availability. For example, geostationary satellites orbit the Earth above the equator traveling at a speed equal to the Earth's rotation in order to maintain a constant location above the Earth. These high orbit satellites (e.g., $\mathrm{GOES}^{6}$ ) are extremely useful for meteorological applications because they offer continuous coverage over the same area. They are limited by their inability to gather information over polar regions as well as their low spatial resolutions. Because of this low spatial resolution, they are not suitable for road studies.

\footnotetext{
${ }^{6}$ http://goes.gsfc.nasa.gov
}

Alternatively, polar orbiting satellites, such as MODIS's Terra and Aqua ${ }^{7}$ or Landsat ETM ${ }^{8}$, are useful for mapping, earth science, or surveillance tasks because they acquire information over every part of the Earth's surface. They offer a variety of temporal and spatial resolutions depending on their altitude and velocity.

\subsubsection{Airplane}

Aerial platforms offer higher spatial resolutions than many satellite products with greater tasking flexibility. They are commonly used for remote sensing applications in multiple disciplines, from military to environmental. Airplanes can be fitted with various sensors and recording devices and gather operational data from altitudes ranging from approximately $300-13,000 \mathrm{~m}^{9}$ [20].

\subsubsection{Unmanned aerial vehicle}

Unmanned aerial vehicles (UAV) are capable of providing high resolution, near real-time imagery often with less expense than manned aerial or spaceborne platforms. For example, [35] illustrated how a UAV system can capture images to map roads and vehicles and provide information regarding traffic, accidents, or natural disasters within 2 hours of the event. [150] were able to identify defects such as rutting, washboarding, and potholes on unpaved roads using pattern recognition and image classification techniques from 2D images collected from a UAV. [152] developed a UAV based system to collect 3D high resolution photogrammetric imagery of road surface distresses for unpaved roads. Their quick response times, high maneuverability and resolutions make them important tools for disaster assessment [123]. [10] designed a low cost UAV with a photogrammetric payload for use after natural disasters to estimate and identify infrastructure damages.

\footnotetext{
${ }^{7}$ http://modis.gsfc.nasa.gov

${ }^{8} \mathrm{http}: / /$ landsat.gsfc.nasa.gov

${ }^{9}$ http://eros.usgs.gov
} 


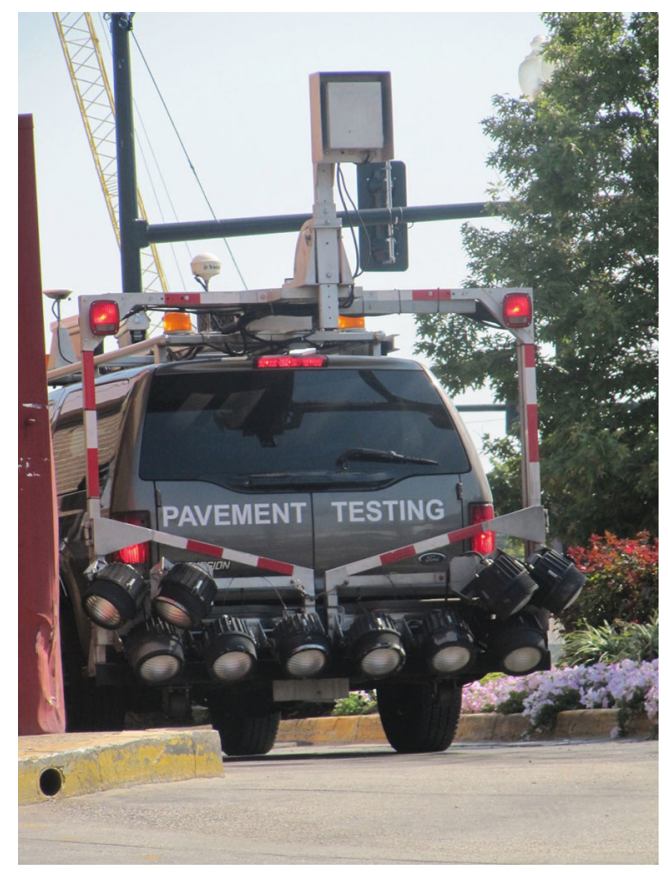

Fig. 3 Road assessment in Washington, DC

\subsubsection{Vehicle}

Multi-purpose survey vehicles are employed worldwide for pavement evaluation (Fig. 3). Sophisticated survey vehicles offer integrated platforms where multiple conditions such as texture, cracking, rutting can be captured. ${ }^{10}$ Vehicular platforms are useful because continuous, high resolution data can be gathered at highway speeds without traffic disruption. They are also capable of collecting data under trees and bridges which would otherwise be obscured from aerial or satellite views.

Data collection is gathered using various methods including laser scanners, photo or video cameras, GPR, thermal, or acoustics to identify distresses. [40] designed an automatic pavement distress survey system mounted onboard a vehicle. They collected data by illuminating the road surface with an argon laser light, scanning the illuminated surface using a laser scanner, and recording the profile data in video. GPR data is also collected from vehicular platforms. [77, 109] utilized a van-mounted, air-horn antenna to collect GPR data for road evaluations. [131] illustrated how 3D LiDAR data of the pavement surface can be gathered at highway speeds from van-mounted equipment.

\footnotetext{
${ }^{10} \mathrm{http}: / /$ yottadcl.com
}

\section{Remote sensing methods applicable to road assessment}

\subsection{Unpaved roads}

Although approximately a third of the roads in the US are unpaved, few studies specifically address remote sensing methods for assessing unpaved road conditions. ${ }^{11}$ While the costs associated with their initial construction are less compared to flexible or rigid pavements, unpaved roads require more frequent assessment because their condition can deteriorate quickly. This additional monitoring often results in increased expenses [11].

Many of the common defects found on unpaved roads (as described in Section 3.3.1) can be identified using remote sensing methods. Digital photos taken from low altitude manned aerial, UAV, or vehicular platforms provide data with appropriate resolutions for identifying distress such as potholes, ruts, and corrugations as well as changes in road surface elevation [13]. The monitoring of unpaved roads is also accomplished by gathering data from lasers, accelerometers, and videos [11].

Using data collected from the visible region of the EM spectrum (eg. photographs), and techniques such as pattern identification, it is possible to identify common defects like rutting, washboarding, or potholes, as well as changes in texture or color which can be indicative of a loss in aggregate materials [106]. Construction of 3D profiles using lasers can contribute to the identification of the road crown as well as potholes. For example, [152] used a UAV and photogrammetric methods to create a $3 \mathrm{D}$ model of surface distress, such as ruts and potholes, with a resolution up to $5 \mathrm{~mm}$ for unpaved roads. Unpaved roads will deteriorate rapidly in conditions of excessive water or moisture. [92] illustrated how a Noise-Modulated Ground Penetrating Radar (GPR) may provide a fast, quantitative approach to identifying moisture in unpaved roads, which is useful for determining if roads are able to sustain heavy vehicular traffic after flooding as well as identifying possible road failures from excessive moisture.

\subsection{Paved roads}

\subsubsection{Visible}

Visual methods of pavement assessment, either manual or automatic, are the most common approaches to detecting and classifying surface defects as well as identifying large scale damage from natural or human disasters. These data are collected in multiple ways including, 1D and 2D line scanners on-board moving vehicles as well as from aerial

\footnotetext{
${ }^{11}$ http://www.fhwa.dot.gov
} 
and satellite photos or images. Automatic detection methods are faster and easier to apply to multiple images than manual image interpretation. Automatic interpretation comprises image processing and pattern recognition techniques to identify defects and distresses [58, 86]. When multitemporal images are available, change detection techniques are commonly used to identify large scale infrastructure damage after disasters [115].

Image processing methods can be used to isolate the defect(s) from the background and create a binary image. The identification and classification of pavement distress is then interpreted from the binary image [42, 69, 97, 148]. Wavelet and Fourier transforms as well as segmentation algorithms are common image processing techniques used for pavement and concrete assessment. Two primary segmentation methods utilized for pavement distress identification are edge-detection and thresholding [100, 115, 127]. [61, 101] applied edge-detection algorithms such as Canny and fast Haar tranforms for crack identification [17]. [68] utilized image segmentation and texture analysis to identify potholes. [110] developed a methodology which included the use of wavelets, segmentation, and thresholding to detect and classify four types of cracking: longitudnal, transverse, block, and alligator, in flexible pavement [100].

The detection of cracks using image processing techniques is difficult because not only do cracks represent a very small portion of the overall image, but also, the road surface texture can disguise irregularities [18]. The automatic detection of pavement distress becomes more complex for images with changes in lighting or with shadows, for roads with variations in surface textures, as well as for roads with variations in their surface's reflectivity. Also, a simple visual interpretation does not provide information of subsurface failures.

[120] proposed a method for pavement inspection which combines a camera with a laser range finder. They collected pairs of images taken from the same perspective, but with different lighting, to determine crack depth while also increasing the accuracy of the distress assessment. By utilizing two lighting schemes, the issues related to poor lighting, shadows, and reflectivity from the surface were reduced.

Digital imagery and processing can be expensive and hampered by lighting restrictions. Photogrammetry is a lowcost option which offers 3D information and is now being used for pavement assessment. [2, 65] demonstrate how low-cost photogrammetry can accurately recreate pavement surfaces and locate cracks and potholes in 3D.

\subsubsection{Ground penetrating radar}

Ground penetrating radar (GPR) employs electromagnetic energy in the microwave range, utilizing wavelengths (3m$200 \mathrm{~mm}$ ) to examine subsurface features with either a ground-coupled antenna $(3 \mathrm{~m}-60 \mathrm{~cm})$ or air-coupled antenna (300-200mm) [109]. Because of differing dielectric constants - especially due to the sensitivity of RADAR to water - changes in materials, moisture contents, and voids may be detected in the returned signal.

GPR can be an effective tool for assessment because it can be operated on-board a moving vehicle traveling at highway speeds, allowing for rapid assessment of road conditions. The most popular and useful applications of GPR in pavement management include the measurement of pavement layer thickness and void discovery [77, 90, 109].

Appraising pavement thickness provides crucial information for establishing load ratings and estimating pavement life by detecting changes in the pavement structure. In situ testing of pavement thickness requires lane closures and can be expensive and time consuming. Using GPR, the thickness of each pavement layer is estimated as a function of the RADAR velocity and the round trip travel time of the signal. Although GPR is a successful tool for measuring the thickness of asphalt pavement [135], the inherent characteristics of Portland cement concrete (PCC) pavement do not yield similar results. PCC has higher moisture and salt contents resulting in RADAR attenuation [15, 77]. Also, the similarity between the dielectric constants of PCC and base materials make distinguishing between the two layers difficult.

Locating voids - both water and air, can be extremely valuable, as moisture between asphalt layers or between the asphalt and base layers is a precursor of pavement deterioration. Moisture related surface distress includes cracking, potholes, rutting, shoving, and raveling [66]. [37] found GPR to be useful for identifying cracks in flexible pavement and measuring crack depths ranging from $50 \mathrm{~mm}$ to $160 \mathrm{~mm}$. This non-destructive technique can be more favorable than the traditional, destructive coring methods for crack depth measurement. [28, 49] were able to identify moisture in the subgrade of flexible pavements using GPR. The early identification of cracks and their depth as well as areas of moisture is crucial for early maintenance and remediation. Recent testing of GPR with a multiple antenna array illustrated its application in identifying moderate to severe stripping, a common cause in pavement delamination [51].

Although GPR can provide valuable data, the signal is complex and requires skilled technicians to interpret the results. Moreover, it only identifies or detects changes in subsurface features, without providing their dimensions.

\subsubsection{Infrared thermography}

While both GPR and infrared (IR) thermography are effective for locating voids, each technique has its own inherent limitations [78]. GPR is capable of portraying the depth and thickness of subsurface irregularities, but it does not provide 
accurate horizontal dimensions. In contrast, it is possible to obtain horizontal measurements of voids using infrared thermography, but the technique does not provide depth or thickness measurements [139].

Infrared thermography operates by measuring the amount of radiation emitted from an object in the infrared range $(9-14 \mu \mathrm{m})$. The measured radiation is a function of the object's emissivity and temperature, along with surrounding weather and atmospheric conditions. IR thermography is used in multiple medical, construction, and military applications for the identification of thermal irregularities or contrasts.

[102] found IR thermography to be useful for evaluating defects in asphalt pavements. As asphalt ages, the decrease of its oily constituents instigates an increase in surfacing limestone. By utilizing limestone's high absorption at $11.2 \mu \mathrm{m}$ they were able to identify areas of deterioration. This technique is not applicable in urban areas because of reflected radiation from the heat island effect. [91] identified cracks and regions of delamination in airport pavements by identifying areas with at least a $0.5^{\circ} \mathrm{C}$ temperature differentiation which was exhibited between defects and surrounding materials. IR thermography was also utilized by [31] to identify non-emergent defects in asphalt pavement.

Reflected radiation from the surrounding area, atmospheric absorption of radiation, and outdoor features such as wind, rain or sunlight all affect local temperatures and will increase the complexity of IR thermographic interpretation [23].

\subsubsection{LiDAR and terrestrial laser scanning}

Similar to RADAR technology, which uses microwave or radio waves, LiDAR (Light Detection and Ranging) captures details by illuminating an area using light from the near-infrared region (approximately $1.0 \mu \mathrm{m}$ ) and measuring the travel time between the transmission of the signal and its reflection or scatter back. The infrared light is commonly emitted at a rate of 5,000 pulses per second [4, 19]. This results in a dense cloud of points in $\mathrm{x}, \mathrm{y}$, and $\mathrm{z}$ positions which are highly accurate and precise. LiDAR is often used for mapping topography and the creation of digital elevation models. When mounted on a moving vehicle, road surfaces can be mapped using the dense and accurate 3D LiDAR point cloud [89]. Unlike other techniques, such as photogrammetry, LiDAR is not restricted by the sun angle and can be implemented during the day or night.

Recently, LiDAR has been applied in pavement evaluation projects. [19] illustrates how LiDAR and a grid-based processing approach can be applied to pavement distress features, such as potholes, to identify and estimate their volume to calculate the amount of fill material needed. LiDAR
3D surface models can be used to identify uneven or low areas susceptible to drainage problems and flooding within a $2 \mathrm{~cm}$ elevation accuracy [131].

Terrestrial laser scanning (TLS) is being utilized for the evaluation of pavement surface conditions. Mounted on-board a moving vehicle and used in conjunction with a digital camera, a laser line scanner is used to construct high resolution, 3D continuous pavement surveys. [73] detected distortions, rutting, shoving, and potholes, in asphalt pavement using high-speed 3D transverse scanning. [128] successfully recognized cracks of $2 \mathrm{~mm}$ and greater in asphalt pavements. [145] demonstrated the use of a multisensor, laser scanning method for the detection of cracks by fusing laser line scanned data with video to produce a 3D model of a road surface which identified cracks of a few $\mathrm{cm}$ as well as their depth. [130] were able to detect faulting in the joints of concrete pavements with an error of less than $1 \mathrm{~mm}$. [138] have developed a prototype pavement data collection system that uses multiple laser scanners to identify surface distress, rutting, roughness, macro-texture and road geometry at a $1 \mathrm{~mm}$ resolution collected at highway speeds which processes in real-time. [103] utilized a laser line scanning system to assess surface texture and skid resistance. [25] found automated pavement surveys to be safer and less labor intensive than manual collection methods while still providing results consistent with standard techniques.

TLS produces high resolution, continuous transverse pavement profiles and it is insensitive to lighting conditions (day, night, or shadow) or low contrast conditions [126]. The high cost of the TLS instrumentation and hardware may make its implementation cost prohibitive.

\subsubsection{Hyperspectral}

Hyperspectral imagery utilizes large numbers of narrow, contiguous spectral bands (sometimes ranging from as much $.35-2.4 \mu \mathrm{m})$ to gather detailed spectral information, often regarding chemical and mineral properties, of an observed feature [24, 48, 55, 105]. Because spectroscopic data can provide information regarding the properties of asphalt surfaces, hyperspectral techniques offer unique opportunities to evaluate road characteristics [45].

Asphalt pavement is composed of hydrocarbons which age and deteriorate as they react with the environment (oxygen, solar radiation, heat), resulting in a decrease of oily constituents and changes in composition [9]. This decrease in hydrocarbon constituents results in an increase in the reflectivity of asphalt [55]. [53, 56] compared imaging and ground spectrometry with in situ pavement condition surveys and found a greater than $10 \%$ increase in asphalt reflectance in the near-infrared (NIR) and short wavelength 
Table 1 Summary of typical unpaved road defects and remote sensing methods for assessment

\begin{tabular}{lllll}
\hline Distress & Visible & Airplane & UAV & Vehicle \\
\hline Potholes & {$[106,108,151,152]$} & {$[107]$} & {$[107,151,152]$} & {$[12]$} \\
Rutting & {$[106,108,151,152]$} & {$[107]$} & {$[107,151,152]$} & {$[12]$} \\
Corrugations & {$[106,108,150]$} & {$[107]$} & {$[107,150]$} & {$[12]$} \\
Erosion and Gravel Loss & {$[106,108]$} & {$[107]$} & {$[107]$} & {$[12]$} \\
Pulverization & {$[106,108]$} & {$[107]$} & {$[107]$} & {$[12]$} \\
\hline
\end{tabular}

infrared (SWIR) for aged pavement compared to new pavement. Although the distinction between new and aged pavement was evident when comparing their spectral signals, distinguishing the degree of weathering of an aged pavement was more difficult, even when substantial changes were evident in the in situ PCI and SI indexes. Aged pavement spectral signals become more complex when cracks in the asphalt expose unweathered materials, which have a lower reflectivity. Shadows from surface roughness were also shown to decrease reflectivity in the NIR and SWIR as much as $7 \%-8 \%$ [53].

[7] found road surface reflectivity governed by not only pavement age, but material quality and road circulation and that a principal component analysis (PCA) performed well at distinguishing between asphalt conditions. Specifically, circulation was found to increase reflectivity while simultaneously causing deterioration, the degree of which was dependent on material quality. This led to an overlapping in spectral signatures in some instances. Using the combined conditions of age, circulation, and material quality they were able to create 5 general categories of road conditions ranging from very good to poor.

Hyperspectral imagery cannot replace an experienced road inspector. For example, cracks expose unweathered material so the differentiation between moderate to severely weathered pavements is not a straightforward process. However, it does offer insights into surface conditions and can reduce the number of areas where the use of destructive and time consuming testing is needed.

\subsubsection{Emerging techniques}

New remote sensing and data collection techniques are emerging, often taking advantage of the extensive use of internet mobile devices. For example, [85, 88] designed systems which reside on smart phones to detect potholes and bumps using accelerometer and GPS data. The city of Boston, MA uses "Street Bump" a new mobile phone app to detect potholes. The app utilizes wavelets and Kruskal's algorithm to detect potholes and then sends a message along with a location to a centralized database. ${ }^{12}$

\footnotetext{
${ }^{12} \mathrm{http}: / /$ www.informationweek.com
}

Other unique methods include an acoustic technique for evaluating pavement surface conditions by collecting sounds generated by tires from a vehicle mounted microphone [153]. [121] evaluated flexible pavement conditions using a phase array Synthetic Aperture Radar (SAR). They found that an increase in backscattering in the $\mathrm{HH}$ polarization signified poor surface pavement conditions and translated well as a ride quality evaluator with an assessment accuracy of $97 \%$ [121].

\subsection{Summary matrices}

A summary of recent research regarding the use of remote sensing techniques for pavement assessment is included in the following tables. Table 1 summarizes research regarding unpaved roads, while Tables 2 and 3 illustrate work concerning flexible and rigid pavements, respectively. It is apparent the majority of work concerns crack identification using visible inspections. This is especially evident for flexible pavements from vehicular platforms.

This inequality in methods and research agendas may be attributed to a number of factors. For example, the vast majority of research concerns flexible pavements versus unpaved roads or rigid pavements and is likely due to the larger use of flexible pavement in the US. The lack of research regarding unpaved roads is also likely the result of its lower cost as well as its locations in more rural, less traveled areas.

Although the selection of an appropriate remote sensing technique can be problem specific, the abundance of research concerns visible methods. Visible surveys are traditional, familiar, and often less expensive than other methods. Techniques such as TLS or LiDAR can require expensive equipment as well as trained technicians and, therefore, may be slower to integrate into management programs.

\section{Hazard assessment}

While multiple regions of the electromagnetic spectrum provide opportunities to detect, assess, and measure defects and deterioration in pavement resulting from normal use and 


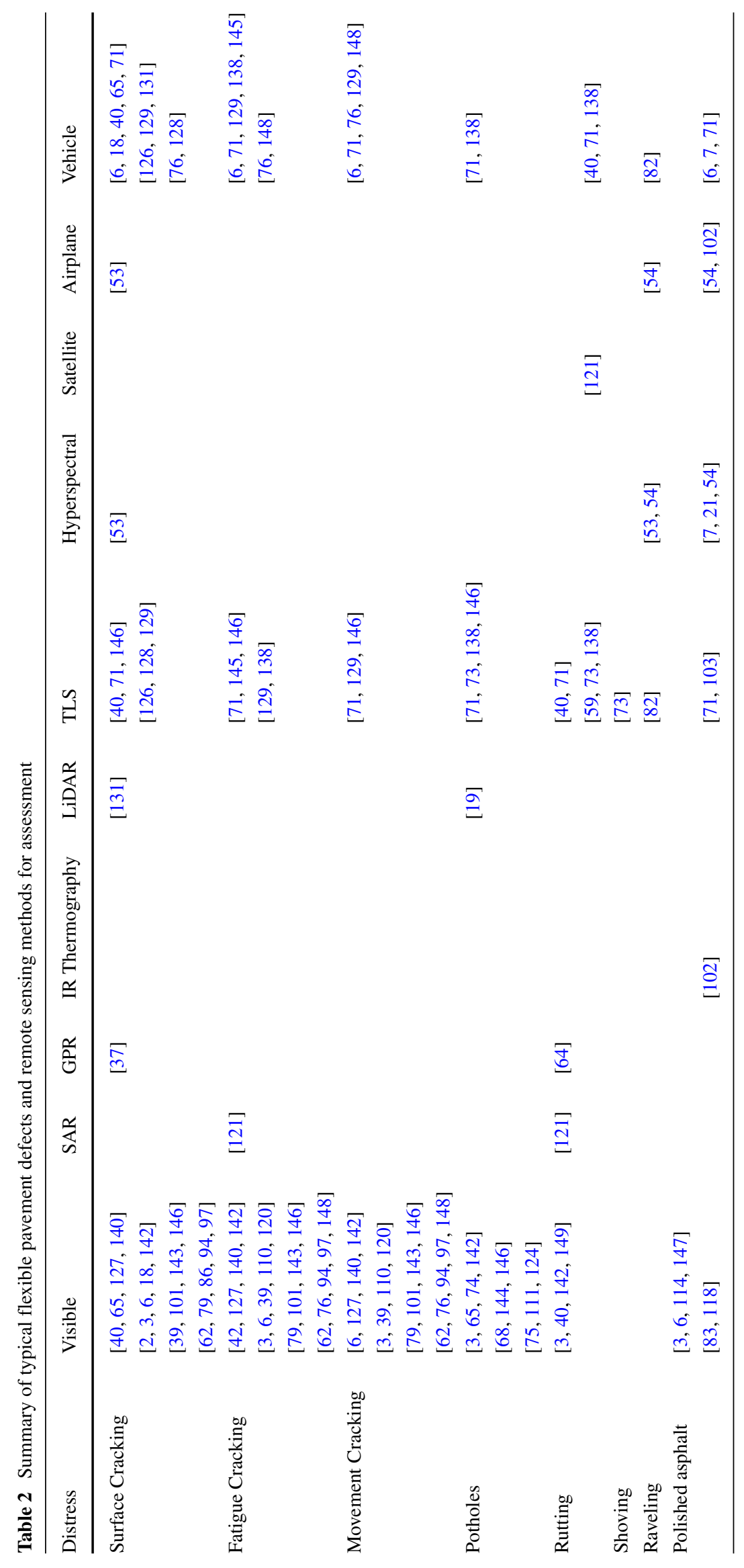


Table 3 Summary of typical rigid pavement defects and remote sensing methods for assessment

\begin{tabular}{|c|c|c|c|c|}
\hline Distress & Visible & TLS & Airplane & Vehicle \\
\hline Surface Cracking & {$[5,6,61]$} & & {$[20]$} & [6] \\
\hline Durability Cracking & {$[5,6,61]$} & & & {$[6]$} \\
\hline Cluster Cracking & {$[5,6,61]$} & & & [6] \\
\hline Diagonal Cracking & {$[5,6,61]$} & & & {$[6]$} \\
\hline Faulting & & {$[130]$} & & [130] \\
\hline Spalling & {$[61,141]$} & & & \\
\hline Punch-outs & [141] & & & \\
\hline
\end{tabular}

weathering; the use of remote sensing methods for assessing roads during and after hazard events is relatively new. Remote sensing has been used for decades to detect and locate floods, forest fires, landslides, and many other hazards of varying type and spatial scale. It is also widely utilized to survey damage to buildings and infrastructure following disasters. The use of remote sensing to specifically assess road damages and accessibility is a relatively new research agenda. While a functioning transportation network is essential in day-to-day life, it is particularly critical during and after hazard events. Information regarding accessibility or obstructed and damaged roadways and bridges is imperative for emergency responders. Natural hazards range in scale from localized landslides affecting a road segment to large regional events such as hurricanes or earthquakes. Because remote sensing methods can provide data with high spatial resolution as well as for inaccessible areas, these data may be used to provide valuable information for the detection and assessment of transportation networks.

Historically, pavement and structural damage from hazards were tested in the field. For example, undetected damage to pavements and roadbeds caused by extensive flooding after Hurricanes Katrina and Rita in Louisiana were evaluated using field techniques such as falling weight deflectometers to assess the structural integrity of road beds by comparing pre- and post-Pavement Condition Indices (PCI) [52, 154]. [29] cataloged road and bridge damages after Hurricane Ivan with photographs from the field.

Recent studies have focused on the application of remote sensing data after earthquakes or flooding to assess transportation networks. [16] used multi-sensor, multi-temporal imagery to identify flooded roads. [33] identified infrastructure and road damage after the 2008 Wenchuan earthquake, using pre- and post-disaster very high resolution (VHR) optical imagery ( $1 \mathrm{~m}$ or better). The combination of optical satellite imagery with a digital elevation model (DEM) to assess roads for accessibility after flooding was used to create a model for application in near-real time for emergency managers [38].
The evaluation and identification of transportation regions vulnerable to disruption is also important. LiDAR has been utilized to quantify slope movement and to predict and measure landslides as well as rockfall and other hazards and instabilities along roadways [30, 70, 116]. LiDAR has also been used with optical remote sensing images for posthazard assessment of structural damage of buildings [98]. Satellite data are extremely useful for disaster assessment especially when before and after imagery is available for change detection [131].

Researchers are also studying new and innovative ways to optimize road assessments following natural disasters. ${ }^{13}$ This new research agenda, funded by the U.S. Department of Transportation, utilizes on-the-ground information culled from social media to identify possible areas of road damage. Once these areas are identified, commercial satellites can be tasked to collect information for designated regions.

\section{Future directions}

\subsection{Traffic cameras}

Traffic cameras may provide a possible new resource for gathering pavement data remotely. They are currently utilized by hundreds of cities in the US to provide real-time information regarding congestion and accidents. Additional or new pavement information could be taken by the cameras during periods of low traffic volume when roads are more visible. Currently, there has been no research investigating the use of traffic cameras for pavement assessment.

\subsection{Volunteered geographic information}

Volunteered geographic information (VGI) is a new and rapidly growing data source frequently available through social media. These data, which are voluntarily contributed and contain spatial and temporal information, harness the power of "humans as sensors" [46]. As a source of real-time,

\footnotetext{
${ }^{13}$ http://trid.trb.org/view/2012/P/1263871
} 
on the ground data VGI has the potential to be a valuable source for pavement monitoring. For example, systems which allow the public to report pavement defects, such as potholes, provide cities or municipalities with valuable, free information $[63,80]$.

\subsection{Ground data integration}

Pavement management systems which concurrently employ ground and remote sensing data may provide the most effective way of assessing and managing the nation's huge transportation infrastructure. Data fusion processes could be utilized to integrate multiple data sources, such as VGI, videos from traffic cameras, and ground data gathered by traditional methods, to increase accuracy and provide a more complete representation than what would be obtained from single data sources.

\section{Conclusions}

One of the most valuable, extensive, and important resources in the US and Europe is their roads. Assessment and monitoring is crucial to maintaining a safe and effective road system. There are multiple surface and subsurface indicators of distress and defects which are observed using traditional, geotechnical engineering methods. While effective, many of these methods can be time consuming, laborious, destructive, costly, and provide information for only limited areas. The use of remote sensing techniques offers new potential for pavement managers to assess large areas, often in little time. Although remote sensing techniques can never entirely replace traditional geotechnical methods, they do provide an opportunity to reduce the number or size of areas requiring site visits or manual methods. Employing remote sensing methods to evaluate pavement and transportation networks during and after natural or manmade disasters can also provide comprehensive information for emergency managers.

Acknowledgments Work performed under this project has been partially funded by the Office of Naval Research (ONR) award \#N00014-14-1-0208 (PSU \#171570).

Open Access This article is distributed under the terms of the Creative Commons Attribution License which permits any use, distribution, and reproduction in any medium, provided the original author(s) and the source are credited.

\section{References}

1. AASHTO (2009) Rough Roads Ahead: Fix Them Now or Pay for it Later. Joint publication of the American Association of State
Highway and Transportation Officials and National Transportation Research Group, Washington, DC

2. Ahmed M, Haas C (2010) The potential of low cost close range photogrammetry towards unified automatic pavement distress surveying. In: Transportation research board annual meeting 2010

3. Ahmed MF, Haas C, Haas R (2011) Accurate and less expensive pavement distress surveying using multi-photogrammetricoutput fusion 2. In: Transportation Research Board 90th Annual Meeting, 11-4312

4. Al-Turk E, Uddin W (1999) Infrastructure inventory and condition assessment using airborne laser terrain mapping and digital photography. Transp Res Rec J Transp Res Board 1690(1):121125

5. Amarasiri S, Gunaratne M, Sarkar S (2009) Modeling of crack depths in digital images of concrete pavements using optical reflection properties. J Transp Eng 136(6):489-499

6. Amarasiri S, Gunaratne M, Sarkar S, Nazef A (2010) Optical texture-based tools for monitoring pavement surface wear and cracks using digital images. Transp Res Rec J Transp Res Board 2153(1):130-140

7. Andreou C, Karathanassi V, Kolokoussis P (2011) Investigation of hyperspectral remote sensing for mapping asphalt road conditions. Int J Remote Sens 32(21):6315-6333

8. AUSTROADS (1991) Road maintenance practice. Austroads, Sydney NSW 2000, www.austroads.com.au

9. Bell C (1989) Summary report on aging of asphalt-aggregate systems. Strategic Highway Research Program Publication SHRPA-305. Technical Report

10. Bendea H, Boccardo P, Dequal S, Giulio Tonolo F, Marenchino D, Piras M (2008) Low cost UAV for post-disaster assessment. In: Proceedings of the XXI congress of the international society for photogrammetry and remote sensing, Beijing (China), pp 3-11

11. Brooks C, Colling T, Kueber M, Roussi C (2011a) State of the practice of unpaved road condition assessment, Deliverable 2-A. In: Characterization of Unpaved Road Conditions Through the Use of Remote Sensing, Michigan Tech Transportation Institute

12. Brooks C, Colling T, Kueber M, Roussi CEA (2011b) Characterization of unpaved road conditions through the use of remote sensing deliverable 2-A: State of the Practice of Unpaved Road Condition Assessment

13. Brooks C, Colling T, Roussi C (2011c) Requirements for remote sensing assessments of unpaved road conditions, Deliverable 1A: In: Characterization of Unpaved Road Conditions Through the Use of Remote Sensing, Michigan Tech Transportation Institute

14. Buck AD (1977) Recycled concrete as a source of aggregate. Am Concr Inst Mater J 74(5):212-219

15. Bungey J (2004) Sub-surface radar testing of concrete: a review. Constr Build Mater 18(1):1-8

16. Butenuth M, Frey D, Nielsen A, Skriver H (2011) Infrastructure assessment for disaster management using multi-sensor and multi-temporal remote sensing imagery. Int J Remote Sens 32(23):8575-8594

17. Canny J (1986) A computational approach to edge detection. IEEE Trans Pattern Anal Mach Intell 6:679-698

18. Chambon S, Moliard JM (2011) Automatic road pavement assessment with image processing: review and comparison. International Journal Geophysics, 2011

19. Chang K, Chang J, Liu J (2005) Detection of pavement distresses using 3D laser scanning technology. In: Proceedings of the 2005 ASCE International Conference on Computing in Civil Engineering 
20. Chen S, Rice C, Boyle C, Hauser E (2011) Small-format aerial photography for highway-bridge monitoring. J Perform Constr Facil 25(2):105-112

21. Chen X, Wang D (2011) Fractal and spectral analysis of aggregate surface profile in polishing process. Wear 271(11):27462750

22. Chou C, McCullough BF (1987) Development of a distress index and rehabilitation criteria for continuously reinforced concrete pavements using discriminant analysis. Transportation Research Record (1117)

23. Clark M, McCann D, Forde M (2003) Application of infrared thermography to the non-destructive testing of concrete and masonry bridges. NDT E Int 36(4):265-275

24. Clark R et al (1999) Spectroscopy of rocks and minerals, and principles of spectroscopy. Man Remote Sens 3:3-58

25. Cline G, Shahin M, Burkhalter J (2003) Automated data collection for pavement condition index survey. In: Annual meeting of Transportation Research Board

26. CSIR (1986) Standard nomenclature and methods for describing the condition of jointed concrete pavements, TRH9. Council for Scientific and Industrial Research, Pretoria

27. CSRA (1985) Nomenclature and methods for describing the condition of asphalt pavements, TRH6. Committee of State Road Authorities, Pretoria

28. Diefenderfer B, Mokarem D, Sharp S (2006) Use of nondestructive evaluation to detect moisture in flexible pavements

29. Douglass S, Hughes S, Rogers S, Chen Q (2004) The impact of Hurricane Ivan on the coastal roads of Florida and Alabama: a preliminary report. Mobile, Alabama: University of South Alabama, Coastal Transportation Engineering Research \& Education Center, $19 \mathrm{p}$

30. Duffell C, Rudrum D (2005) Remote sensing techniques for highway earthworks assessment. Proceedings, Geo-Frontiers, p 2005

31. Dumoulin J, Ibos L, Marchetti M, Mazioud A (2011) Detection of non emergent defects in asphalt pavement samples by long pulse and pulse phase infrared thermography. Eur J Environ Civil Eng 15(4):557-574

32. Edil TB, Benson CH, Bin-Shafique MS, Tanyu BF, Kim WH, Senol A (2002) Field evaluation of construction alternatives for roadways over soft subgrade. J Transp Res Board 1786:36-48

33. Ehrlich D, Guo H, Molch K, Ma J, Pesaresi M (2009) Identifying damage caused by the 2008 Wenchuan earthquake from VHR remote sensing data. Int J Digit Earth 2(4):309-326

34. Faiz A, Yoder EJ (1974) Factors influencing the performance of continuously reinforced concrete pavements. Transportation Research Record (485)

35. Feng W, Yundong W, Qiang Z (2009) UAV borne real-time road mapping system. In: Urban Remote Sensing Event, 2009 Joint. IEEE, pp 1-7

36. FHWA (1984) Construction handbook on PCC pavement rehabilitation. US Department of Transportation, Federal Highway Administration

37. Forest R, Utsi V (2004) Non destructive crack depth measurements with ground penetrating radar. In: Ground Penetrating Radar, 2004. GPR 2004. Proceedings of the Tenth International Conference on. IEEE, pp 799-802

38. Frey D, Butenuth M (2011) Trafficability analysis after flooding in urban areas using probabilistic graphical models. In: Urban Remote Sensing Event (JURSE), 2011 Joint. IEEE, pp 345348

39. Fu P, Harvey JT, Lee JN, Vacura P (2011) New method for classifying and quantifying cracking of flexible pavements in automated pavement condition survey. Trans Res Rec: J Trans Res Board 2225(1):99-108
40. Fukuhara T, Terada K, Nagao M, Kasahara A, Ichihashi S (1990) Automatic pavement-distress-survey system. J Trans Eng 116(3):280-286

41. Fwa TF (2006) The Handbook of Highway Engineering. CRC Press, Taylor

42. Georgopoulos A, Loizos A, Flouda A (1995) Digital image processing as a tool for pavement distress evaluation. ISPRS J Photogramm Remote Sens 50(1):23-33

43. Giroud JP, Noiray L (1981) Geotextile-reinforced unpaved road design. J Geotech Eng Div 107(9):1233-1254

44. Giummarra G et al (2000) Unsealed Roads Manual: Guidelines to Good Practice, USR001. Australian Road Research Board, Transport Research, Vermont South

45. Gomez R (2002) Hyperspectral imaging: a useful technology for transportation analysis. Opt Eng 41(9):2137-2143

46. Goodchild M (2007) Citizens as sensors: the world of volunteered geography. GeoJournal 69(4):211-221

47. Gramling W (1994) Current practices for determining pavement condition. National Cooperative Highway Research Program (NCHRP), Synthesis 203. Transportation Research Board Publication

48. Green R, Eastwood M, Sarture C, Chrien T, Aronsson M, Chippendale B, Faust J, Pavri B, Chovit C, Solis M et al (1998) Imaging spectroscopy and the airborne visible/infrared imaging spectrometer (AVIRIS). Remote Sens Environ 65(3):227-248

49. Grote K, Hubbard S, Harvey J, Rubin Y (2005) Evaluation of infiltration in layered pavements using surface GPR reflection techniques. J Appl Geophys 57(2):129-153

50. Halliday D, Resnick R, Walker J (2010) Fundamentals of physics extended. Wiley

51. Heitzman M, Maser K, Tran NH, Brown R, Bell H, Holland S, Ceylan H, Belli K, Hiltunen D (2013) Nondestructive Testing to Identify Delaminations between HMA Layers, SHRP 2 Report S2-R06D-RR-1. Technical Report

52. Helali K, Eng P, Robson M, Nicholson R, Bekheet W (2008) Importance of a pavement management system in assessing pavement damage from natural disasters: a case study to assess the damage from Hurricanes Katrina and Rita in Jefferson Parish, Louisiana. In: 7th International Conference on Managing Pavement Assets

53. Herold M, Roberts D (2005) Spectral characteristics of asphalt road aging and deterioration: implications for remote-sensing applications. Appl Opt 44(20):4327-4334

54. Herold M, Gardner M, Noronha V, Roberts D (2003) Spectrometry and hyperspectral remote sensing of urban road infrastructure. Online Journal of Space Communications 3

55. Herold M, Roberts D, Gardner M, Dennison P (2004) Spectrometry for urban area remote sensing-Development and analysis of a spectral library from 350 to $2400 \mathrm{~nm}$. Remote Sens Environ 91(3):304-319

56. Herold M, Roberts D, Noronha V, Smadi O (2008) Imaging spectrometry and asphalt road surveys. Trans Res Part C: Emerg Technol 16(2):153-166

57. Hicks R, Mahoney J (1981) Collection and use of pavement condition data. NCHRP Synth 76:1-25

58. Hu M (1962) Visual pattern recognition by moment invariants. Inf Theory, IRE Trans 8(2):179-187

59. Huang Y, Hempel P, Copenhaver T (2011) Texas Department of Transportation 3D transverse profiling system for high speed rut measurement Journal of Infrastructure Systems

60. Huang YH (1993) Pavement Analysis and Design. Prentice Hall Publication

61. Hutchinson T, Chen Z (2006) Improved image analysis for evaluating concrete damage. J Comput Civil Eng 20(3):210-216 
62. Jahanshahi MR, Masri SF, Padgett CW, Sukhatme GS (2013) An innovative methodology for detection and quantification of cracks through incorporation of depth perception. Mach Vision Appl 24:227-241

63. Johnson P, Sieber R (2012) Situating the adoption of vgi by government. Crowdsourcing Geographic Knowledge, pp 65-81

64. Kassem E, Chowdhury A, Scullion T, Masad E (2012) Measurements of asphalt pavement density using ground penetrating radar and its relationship to performance. In: Transportation Research Board 91st Annual Meeting, 12-4051

65. Kertész I, Lovas T, Barsi A (2008) Photogrammetric pavement detection system. In: ISPRS, Citeseer, vol 37, p B5

66. Khosla BBNP, Kawaguchi S (1999) An in-depth evaluation of moisture sensitivity of asphalt mixtures. In: NCDOT Project 1998-08, North Carolina Department of Transportation, Raleigh

67. Kim WH, Edil TB, Benson CH, Tanyu BF (2006) Deflection of prototype geosynthetic-reinforced working platforms over soft subgrade. J Trans Res Board 1975:137-145

68. Koch C, Brilakis I (2011) Pothole detection in asphalt pavement images. Adv Eng Informa 25(3):507-515

69. Koutsopoulos H, El Sanhouri I (1991) Methods and algorithms for automated analysis of pavement images. Pavement Management: Data Collection, Analysis, and Storage (1311)

70. Lato M, Diederichs M, Hutchinson D, Harrap R (2012) Evaluating roadside rockmasses for rockfall hazards using LiDAR data: optimizing data collection and processing protocols. Nat Hazards 60(3):831-864

71. Laurent J, Lefebvre D, Samson E (2008) Development of a new 3D transverse laser profiling system for the automatic measurement of road cracks. In: Proceedings of the 6th International Symposium on Pavement Surface Characteristics. Slovenia

72. Lay MG (2009) Handbook of Road Technology. Spon Press

73. Li Q, Yao M, Yao X, Xu B (2010) A real-time 3D scanning system for pavement distortion inspection. Meas Sci Technol 21(1):015,702

74. Lin J, Liu Y (2010) Potholes detection based on svm in the pavement distress image. In: Distributed Computing and Applications to Business Engineering and Science (DCABES), 2010 Ninth International Symposium on. IEEE, pp 544-547

75. Lokeshwor H, Das LK, Sud SK (2012) Automated detection and measurement of potholes from road surface video clips. Highw Res J 5:9-18

76. Lokeshwor H, Das LK, Sud SK (2013) Automated detection and measurement of cracks from monochrome video clips captured by road network survey vehicle. Indian Highw 41:91-103

77. Maser K (1996) Condition assessment of transportation infrastructure using ground-penetrating radar. J Infrastruct Syst 2(2):94-101

78. Maser K, Roddis W (1990) Principles of thermography and radar for bridge deck assessment. J Trans Eng 116(5):583-601

79. Mathavan S, Rahman M, Kamal K (2012) Application of texture analysis and kohonen map for region segmentation of pavement images for crack detection. Trans Res Rec: J Trans Res Board 2304(1):150-157

80. McDougall K (2010) From silos to networks-will users drive spatial data infrastructures in the future? In: Proceedings of the 24th FIG International Congress (FIG 2010), International Federation of Surveyors (FIG), pp 1-13

81. McGhee KH (2004) Automated pavement distress collection techniques. National Cooperative Highway Research Program (NCHRP), Synthesis 334. Transportation Research Board Publication

82. McRobbie S, Wright A, Iaquinta J, Scott P, Christie C, James D (2010) Developing new methods for the automatic measurement of raveling a traffic-speed. TRL Staff Papers
83. McQuaid G, Millar P, Woodward D, Friel S (2013) Use of close range photogrammetry to assess the micro-texture of asphalt surface aggregate. International Journal of Pavements Conference (IJPC): $1-12$

84. MDOT (2012) Pavement Design and Selection Manual. MDOT Construction Field Services Division. Technical Report

85. Mednis A, Strazdins G, Zviedris R, Kanonirs G, Selavo L (2011) Real time pothole detection using android smartphones with accelerometers. In: Distributed Computing in Sensor Systems and Workshops (DCOSS), 2011 International Conference on. IEEE, pp 1-6

86. Mei A, Manzo C, Bassani C, Salvatori R, Allegrini A (2014) Bitumen removal determination on asphalt pavement using digital imaging processing and spectral analysis. Open J Appl Sci 4:366-374

87. Miller J, Bellinger W (2003) Distress identification manual for the long-term pavement performance program. Federal Highway Administration Report. FHWA-RD-03-031. Technical Report

88. Mohan P, Padmanabhan V, Ramjee R (2008) Nericell: rich monitoring of road and traffic conditions using mobile smartphones. In: Proceedings of the 6th ACM Conference on Embedded Network Sensor Systems. ACM, pp 323-336

89. Moreno F, Gonzalez-Jimenez J, Blanco J, Esteban A (2013) An instrumented vehicle for efficient and accurate 3D mapping of roads. Comput-Aided Civil Infrastruct Eng 28(6):403419

90. Morey R (1998) Ground penetrating radar for evaluating subsurface conditions for transportation facilities, vol 255. Transportation Research Board

91. Moropoulou A, Avdelidis N, Koui M, Kakaras K (2001) An application of thermography for detection of delaminations in airport pavements. NDT E Int 34(5):329-335

92. Muller W, Schuermann A, Reeves B (2012) Quantitative moisture measurement of road pavements using 3D noise-modulated GPR. In: Ground Penetrating Radar (GPR), 2012 14th International Conference. IEEE, pp 517-523

93. NCHRP (1979) Failure and Repair of Continuously Reinforced Concrete Pavements. NCHRP Synthesis of Highway Practice 60. Transportation Research Board, Washington, DC

94. Ni Z, Tang P, Xi Y (2012) A new method to pavement cracking detection based on the biological inspired model. In: Computer Science and Information Processing (CSIP), 2012 International Conference. IEEE, pp 755-758

95. NRC (2006) Geological and Geotechnical Engineering in the New Millennium Opportunities for Research and Technological Innovation. National Academy Press. Publication No. 11558

96. OECD (1990) Road Monitoring for Maintenance Management, Damage Catalogue for Developing Countries, vol II. Organization for Economic Co-operation and Development, Paris

97. Oliveira H, Correia P (2013) Automatic road crack detection and characterization. In: Transactions on Intelligent Transportation Systems 14(1). IEEE, pp 155-168

98. Olsen MJ, Chen Z, Hutchinson T, Kuester F (2012) Optical techniques for multiscale damage assessment. Geomatics, Natural Hazards and Risk 4(1):49-70

99. Olsen MJ, Raugust JD, Roe GV (2013) Use of Advance Geospatial Data, Tools, Technologies, and Information in Department of Transportation Projects, NCHRP Synthesis 446, vol 446. Transportation Research Board

100. Otsu N (1975) A threshold selection method from gray-level histograms. Automatica 11(285-296):23-27

101. Ouyang A, Luo C, Zhou C (2011) Surface distresses detection of pavement based on digital image processing. Computer and Computing Technologies in Agriculture IV, pp 368-375 
102. Pascucci S, Bassani C, Palombo A, Poscolieri M, Cavalli R (2008) Road asphalt pavements analyzed by airborne thermal remote sensing: preliminary results of the Venice highway. Sensors 8(2):1278-1296

103. Peng K, Zhou XL (2011) Research for predicting road skid resistance based on machine vision. In: GeoHunan International Conference 2011

104. PIRAC (1982) International Road Maintenance Handbook, Maintenance of Unpaved Roads, vol II. World Road Association, Paris

105. Roberts D, Herold M (2004) Imaging spectrometry of urban materials. Infrared Spectrosc Geochem, Explor Remote Sens, Miner Assoc Canada, Short Course Ser 33:155181

106. Roussi C, Brooks C (2011) Remote sensing the phenomena of unpaved road conditions, Deliverable 3-A. In: Characterization of Unpaved Road Conditions Through the Use of Remote Sensing. Michigan Tech Transportation Institute

107. Roussi C, Brooks C (2012a) Candidate and recommended remote sensing platforms for unpaved road condition assessment, Deliverable 5-A. In: Characterization of Unpaved Road Conditions Through the Use of Remote Sensing. Michigan Technology Transportation Institute

108. Roussi C, Brooks C (2012b) Sensor selection for use in remote sensing the phenomena of unpaved road conditions, Deliverable 4-A. In: Characterization of Unpaved Road Conditions Through the Use of Remote Sensing. Michigan Technology Transportation Institute

109. Saarenketo T, Scullion T (2000) Road evaluation with ground penetrating radar. J Appl Geophys 43(2):119-138

110. Salari E, Bao G (2010) Pavement distress detection and classification using feature mapping. In: Electro/Information Technology (EIT), 2010 IEEE International Conference. IEEE, pp $1-5$

111. Salari E, Chou E, Lynch JJ (2012) Pavement distress evaluation using 3D depth information from stereo vision. MIOH-UTC Project Identifier: TS 43

112. SANRAI (2000) Routine Road Maintenance Guidance Manual. South African National Road Agency, Pretoria, South Africa

113. Shahin M, Kohn S (1979) Development of a pavement condition rating procedure for roads, streets, and parking lots, volume I, conditions rating procedure. Technical Report, DTIC Document

114. Shalaby A, El Gendy A et al (2011) Method and tool for surface texture evaluation. US Patent $8,085,987$

115. Singh A (1989) Review article: Digital change detection techniques using remotely-sensed data. Int J Remote Sens 10(6):9891003

116. Smedley M, Paulson R, Tucker A (2009) Remote sensing for highway management of landslides. Proc Inst Civil Eng-Geotech Eng 162(3):141-150

117. Smith R, Chang-Albitres C (2007) The impact of semiautomated pavement distribution collection methods on pavement management network-level analysis using the MTC Streetsaver. Report prepared for Metropolitan Transportation Commission by the Texas Transportation Institute, Texas A \& M University System, Project No. 476290

118. Specht LP, Khatchatourian O, Dos Santos RT (2012) Measurement of pavement macrotexture through digital image processing. Acta Sci Technol 35(1):31-38

119. Stuller J (1983) America's decaying highways. Am Legion Mag $115(2)$

120. Su Y, Kang S, Chang J, Hsieh S (2010) Using dual lights for robotic pavement inspection. In: Proceedings of SICE Annual Conference, vol 1
121. Suanpaga W, Yoshikazu K (2010) Riding quality model for asphalt pavement monitoring using phase array type L-band synthetic aperture radar (PALSAR). Remote Sens 2(11):25312546

122. Tanyu BF, Edil TB, Benson CH, Kim WH (2005) Development of methodology to include structural contribution of alternative working platforms in pavement structure. J Trans Res Board 1936:70-77

123. Tatham $P$ (2009) An investigation into the suitability of the use of unmanned aerial vehicle systems (UAVS) to support the initial needs assessment process in rapid onset humanitarian disasters. Int J Risk Assess Manag 13(1):60-78

124. Tiong PLY, Mustaffar M, Hainin MR (2012) Road surface assessment of pothole severity by close range digital photogrammetry method. World Appl Sci J 19(6):867-873

125. TRRL (1985) Maintenance Techniques for District Engineers, Overseas Road Note 2. Transport and Road Research Laboratory, Crowthorne, England

126. Tsai Y, Li F (2012) Critical assessment of detecting asphalt pavement cracks under different lighting and low intensity contrast conditions using emerging 3D laser technology. J Trans Eng 138(5):649-656

127. Tsai Y, Kaul V, Mersereau R (2009) Critical assessment of pavement distress segmentation methods. J Trans Eng 136(1):11-19

128. Tsai Y, Jiang C, Wang Z (2012a) Pavement crack detection using high-resolution 3D line laser imaging technology. In: 7th RILEM International Conference on Cracking in Pavements. Springer, pp 169-178

129. Tsai YC, Jiang C, Huang Y (2012b) A multi-scale crack fundamental element model for real-world pavement crack classification. Journal of Computing in Civil Engineering

130. Tsai YJ, Wu Y, Ai C, Pitts E (2012c) Critical assessment of measuring concrete joint faulting using $3 \mathrm{D}$ continuous pavement profile data. Journal of Transportation Engineering

131. Uddin W (2011) Remote sensing laser and imagery data for inventory and condition assessment of road and airport infrastructure and GIS visualization. Int J Roads Airports 1(1):53-67

132. USDOT (2003) Standard Specifications for Construction of Roads and Bridges on Federal Highway Projects. USDOT, FWHWA Publication No. FHWA-FLH-03-002. Technical Report

133. USDOT (2006) Promoting Geosynthetics Use on Federal Lands Highway Projects. USDOT, Central Federal Lands Highway Division, FWHWA Publication No. FHWA-CFL/TD-06-009. Technical Report

134. Van Wijk AJ (1985) Rigid Pavement Pumping. JHRP-85-10, Indiana Department of Highways, West Lafayette, IN. Technical Report

135. Varela-González M, Solla M, Martínez-Sánchez J, Arias P (2014) A semi-automatic processing and visualisation tool for ground-penetrating radar pavement thickness data. Autom Constr 45:42-49

136. VDOT (2012) A guide to evaluating pavement distress through the use of digital images. Virginia Department of TransportationMaintenance Division, Richmond, VA, November, Version 2

137. Wade M, Cuttell G, Vandenbossche J, Yu H, Smith K, Snyder M (1997) Performance of Concrete Pavements Containing Recycled Concrete Aggregate. Federal Highway Administration, Report No. FHWA-RD-96-164. Technical Report

138. Wang K (2011) Automated survey of pavement distress based on 2D and 3D laser images. MBTC DOT 3023

139. Weil G (1992) Non-destructive testing of bridge, highway and airport pavements. In: Nondestructive Evaluation of Civil Structures and Materials 
140. Xiao W, Yan X, Zhang X (2006) Pavement distress image automatic classification based on density-based neural network. Rough Sets and Knowledge Technology. Springer, pp 685-692

141. Yao X, Yao M, Xu B (2008) Automated detection and identification of area-based distress in concrete pavements. In: 7th International Conference on Managing Pavement Assets

142. Younes G, Hadda C, Attia N, Djelloul Z (2009) Supervised learning and automatic recognition of asphalt pavement deteriorations. In: Computer Systems and Applications, 2009. AICCSA 2009. IEEE/ACS International Conference. IEEE, pp 205-210

143. Youquan H, Hanxing Q, Jian W, Wei Z, Jianfang X (2011a) Studying of road crack image detection method based on the mathematical morphology. In: Image and Signal Processing (CISP), 2011 4th International Congress on, vol 2. IEEE, pp 967969

144. Youquan H, Jian W, Hanxing Q, Wei Z, Jianfang X (2011b) A research of pavement potholes detection based on threedimensional projection transformation. In: Image and Signal Processing (CISP), 2011 4th International Congress, vol 4. IEEE, pp 1805-1808

145. Yu S, Sukumar S, Koschan A, Page D, Abidi M (2007) 3D reconstruction of road surfaces using an integrated multi-sensory approach. Opt Lasers Eng 45(7):808-818

146. Yu X, Salari E (2011) Pavement pothole detection and severity measurement using laser imaging. In: Electro/Information Technology (EIT), 2011 IEEE International Conference. IEEE, pp 1-5

147. Yuan Y, Lai A, Que Y (2009) Application of fractal theory in pavement surface texture measurement. In: ICCTP 2009
Critical Issues in Transportation Systems Planning, Development, and Management, ASCE, pp 1-7

148. Zalama E, Gómez-García-Bermejo J, Medina R, Llamas J (2014) Road Crack Detection Using Visual Features Extracted by Gabor Filters. Comput-Aided Civil Infrastruct Eng 29(5):342358

149. Zandi Y, Akpinar MV, Mehdizadeh M (2012) Assessing permenant deformation of asphalt mixtures using digital imaging. J Basic Appl Sci Res 2:5292-5298

150. Zhang C (2008) An UAV-based photogrammetric mapping system for road condition assessment. In: Proceedings of the International Archives of the Photogrammetry, Remote Sensing and Spatial Information Sciences, ISPRS Congress, pp 627631

151. Zhang C (2009) Monitoring the condition of unpaved roads with remote sensing and other technology. US DOT DTPH56-06BAA-0002

152. Zhang C, Elaksher A (2012) An unmanned aerial vehicle-based imaging system for 3D measurement of unpaved road surface distresses. Comput-Aided Civil Infrastruct Eng 27(2):118129

153. Zhang Y, Ma X, McDaniel J WangM (2012) Statistical analysis of acoustic measurements for assessing pavement surface condition. In: SPIE Smart Structures and Materials+ Nondestructive Evaluation and Health Monitoring, International Society for Optics and Photonics, pp 83,471F-83,471F

154. Zhang Z, Wu Z, Martinez M, Gaspard K (2008) Pavement structures damage caused by Hurricane Katrina flooding. J Geotech Geoenviron Eng 134(5):633-643 